\title{
DOCUMENTOS
}

\section{Aldo Moro en la historia de Italia. Celebración en el centenario de su nacimiento'}

\section{Renato Moro ${ }^{2}$}

Las historias de un país -y por "historias de un país" entiendo aquellas obras de síntesis que reconstruyen sus grandes líneas- son en primer lugar el espejo de las interpretaciones de los estudiosos que las escribieron, pero también son el espejo de más amplios sentimientos e imágenes colectivas y de alguna manera son verdaderas y auténticas autobiografías nacionales.

¿Qué nos dicen nuestras "autobiografías" sobre Aldo Moro? Aunque los papeles de Moro y muchas fotografías y testimonios en relación con Moro transmiten un gran afecto popular, él fue sin duda uno de los líderes más controvertidos que haya tenido Italia. Sobre todo entre los políticos y los intelectuales, encontró feroces críticos y apasionados defensores, siendo amado -e incluso odiado- como pocos. No es de extrañar entonces que las historias de Italia nos ofrezcan de él imágenes fuertemente contrapuestas: el "Giolitti católico", es decir, el político capaz de combinar apertura al "país real" con "clientelismo" mutante; el tejedor del "compromiso histórico", ensalzado por algunos hasta hacer de él un mártir de la apertura a los comunistas y detestado por otros como principal arquitecto de esa hipótesis. Moro, por último, simbolizó la "primera República", a la que encarnó en sus límites, sus méritos y su drama.

\footnotetext{
' Discurso del profesor Renato Moro ante el presidente de la República italiana, Sergio Mattarella, el expresidente Giorgio Napolitano, los presidentes de las magistraturas constitucionales y otras autoridades de la República, en el Palacio del Quirinal de Roma, 23-IX-2016. La traducción se debe a la redacción de RFS con la colaboraicón de Giacomo Veduti, estudiante de Ciencias políticas y de Relaciones internacionales en las universidades de Bolonia y Loyola Andalucía (Córdoba).

${ }^{2}$ Facultad de Ciencias Políticas, Università Roma Tre, Roma.
} 
Estas lecturas tienen dos limitaciones esenciales. En primer lugar, están demasiado ligadas a la lucha política, pues aquéllas comienzan directamente en los tópoi interpretativos surgidos desde los primeros años de las controversias del centro-izquierda, que se reanudaron años después en torno a la solidaridad nacional, por lo que dependen en resumen de la áspera confrontación que hubo en el debate público entre una imagen aún presente en la memoria de un Moro "gattopardesco" y levantino, como lo describió en su día Leonardo Sciascia, y la de un Moro profeta del encuentro con los comunistas y por ello víctima sacrificial de aquella valiente elección. En segundo lugar, estas lecturas están todas ellas dominadas por el "caso Moro", no sólo con una clara desproporción entre el Moro prisionero de las Brigadas Rojas como consecuencia y las muchas décadas anteriores de actividad política, sino también con una paradójica "proyección interpretativa" hacia el pasado consistente en leer la historia de Moro no a partir del comienzo sino del final, como si éste fuese la clave de comprensión de toda la vida.

Pero hemos de tener en cuenta que las contrapuestas interpretaciones acerca de un líder político con la "centralidad" de Moro no son sólo inevitables sino legítimas, como legítimo e inevitable es que, en su nombre y a partir de su experiencia se haya continuado haciendo política. Sin embargo, en algún momento, tenemos que profundizar en nuestros conocimientos, el momento en el que hemos de repetir el grito de Marc Bloch (para nosotros historiadores, nuestro Einstein) a propósito de las controversias sobre la Revolución francesa: "Partidarios y contrarios de Robespierre, os pedimos que nos concedáis una "gracia": por favor, decidnos sólo y simplemente: ¿̇quién fue Robespierre?". Las pasiones civiles han de ejercerse no sólo "en oscuridad", ni distorsionándolas con prejuicios.

Del mismo modo, hemos de aceptar que el "caso Moro" es una herida abierta que necesita verdaderas respuestas: esto no es sólo legítimo sino necesario. Pero también hemos de reflexionar sobre esto y decidir si sus cerca de sesenta y dos años de vida cuentan más que esos cincuenta y cinco días. ¿Pueden éstos "tragarse", como ocurre con frecuencia, una figura y una personalidad?

Recientemente algo ha empezado a cambiar, es cierto, también gracias al compromiso de la Academia de estudios históricos Aldo Moro, y poco a poco ha ido apareciendo una nueva generación de estudiosos, que en 1978 ni siquiera habían nacido, que han comenzado su estudio sobre Moro, más allá de las contraposiciones y esquemas del pasado; por primera vez, en 2011 los escritos sobre los demás aspectos de su vida superaron en número, aunque por poco, a los dedicados a los cincuenta y cinco del secuestro. El debate, sin embargo, no ha hecho más que empezar. 
Hay un episodio que siempre me pareció revelador. La noche anterior al secuestro por las Brigadas Rojas, a la una de la noche Giovanni, el hijo de Moro, le encontró inmerso en la lectura de uno de los grandes textos de la teología del siglo XX: El Dios crucificado del teólogo protestante Jürgen Moltmann. Para quien no conociese a Moro esto tiene algo de sorprendente: un líder político comprometido como él, y en ese momento de forma muy especial, ¿̇cómo podía buscar y encontrar tiempo para este tipo de intereses y necesidades? Esto nos lleva, pues, a reflexionar sobre la complejidad de la figura del Moro y a preguntarnos si, en muchos aspectos, sigue siendo desconocida.

Así, si con ocasión de este centenario se desea realmente honrar su memoria y dar a conocer su perfil a los italianos, me parece que tenemos que superar, en la medida de lo posible, las viejas contraposiciones: hemos de "liberar" a Moro de la "cárcel brigadista" y hay que situar en su trasfondo el drama que acompañó su muerte y ocuparse de él como político, por supuesto, pero también como intelectual, como jurista, como cristiano, como hombre. Después de todo, lo que hace a un político no son sólo las ideas, la escala de valores o la cultura; también marcan la psicología, los afectos, los principios profundos e implícitos, la mentalidad. Justamente Moro, que fue presentado por muchos como un político sin más, siempre luchó para no ser tenido por un "político profesional", reivindicando por mucho tiempo el papel de quien se situase "más allá de la política", como se titulaba un artículo suyo, y sólo con mucha reticencia y bajo fuerte presión aceptó renunciar a la carrera universitaria y ser candidato de la Asamblea constituyente; así mismo Moro, que vivió durante mucho tiempo su compromiso político como algo transitorio, pensó muchas veces en dejarlo, incluso a finales de los años sesenta. Por otra parte, Moro se mostró de forma inmediata como un político "diferente" de los demás. En septiembre de 1965, el director de una importante publicación italiana escribió:

Para mí Moro fue un gran enigma. Este hombre que no quiere ser fotografiado, ni entrevistado, ni citado, que ni siquiera quiere ser alabado, ¿de dónde viene? ¿̇a dónde irá?, ¿cómo demonios ha llegado hasta nosotros?"

Actualmente podemos reconstruir muchos elementos de esa originalidad.

Este líder nacional, y quizá también internacional, era ante todo un hombre "de provincias" y meridional que procedía de una familia de la pequeña burguesía meridional, de maestros asimismo hijos de maestros, entre los orígenes paternos en Salento y maternos en Calabria. Su formación meridional estuvo enriquecida por muchos elementos modernos. Su padre era uno de los mejores expertos italianos sobre la escuela primaria, en particular la escuela rural. Su madre era una convencida defensora de la emancipación de la mujer, escribía en los periódicos 
no sólo locales y daba conferencias. Una común pasión humanitaria unía a sus padres: era el fermento reformista de principios de siglo que abarcaba de Giovanni Cenna a Umberto Zanotti Bianco (Compagnia per gli interessi del Mezzogiorno). La meridionalidad de Moro, a menudo olvidada en los discursos sobre él, es fundamental para la comprensión de muchos aspectos de su personalidad. Moro vio siempre la escuela -como había sido para sus padres- como una oportunidad extraordinaria para unificar Italia y especialmente para la emancipación de las clases más pobres. Moro, como tantos otros del sur, no tuvo ninguna experiencia en la Resistencia el sur y en él la nueva Italia de los Comités de Liberación nacional (CLN) supuso un difícil impacto, convirtiéndose en uno de los intérpretes más cuidadosos y profundos de la protesta meridional. Moro votó republicano, aunque era muy comprensivo con las razones de los monárquicos. Por encima de todo, era un hombre procedente del sur, formado en el sur, que consideraba que el sur del país era una reserva importante y positiva para éste, siempre fue uno de los políticos italianos más atentos al equilibrio del país. Beniamino Andreatta testificó que Moro se refería a Italia con esta metáfora:

el país era como un castillo de naipes; se podía intentar construir un piso de más, pero había que colocar las cartas con gran delicadeza y contener la respiración, pues de lo contrario todo se derrumbaría.

Desde ese punto de vista Moro siempre tuvo en cuenta el valor de aquella parte de de Italia que podía parecer menos avanzada cultural, social, económica o políticamente, pero que ni podía ni debía ser olvidada, pues de lo contrario fallaría todo. Había que recordar que existía un "país profundo" que no era el de las vanguardias intelectuales de Milán o Roma y que podía y debía asimismo contribuir, que estaba llamado y debía contribuir al progreso.

Un segundo punto es su profundísima religiosidad personal. Moro fue también uno de los hombres de cultura más "laica" que formaban parte del catolicismo italiano. Líder del partido democratacristiano, provenía de una familia que, contrariamente a lo que la gente suele decir, no era una familia católica, en la que vio practicar cada día la fe y la laicidad, con una madre muy religiosa, imbuida de un cristianismo abierto a todas las realidades terrenas y arraigado en la lectura diaria del Evangelio y un padre "laico", aunque no anticlerical pero sí crítico de todo dogmatismo. Incluso antes de su acercamiento ciertamente crucial a la Federación Universitaria Católica Italiana, la FUCl de Giovanni Battista Montini, Moro vivió su fortísima experiencia creyente esencialmente como un esfuerzo de apertura a la vida y a lo humano y desde el rechazo de cualquier oposición al "mundo laico". La primera cuestión que Moro, recién nombrado presidente de la FUCl en 1939, sugirió para reflexión de ésta fue el "humanismo cristiano", al que 
en seguida le dio la vuelta como "cristianismo humano", un cristianismo que-como escribió- "hable un lenguaje humano, diga palabras propias de los hombres, que tenga una gran confianza en la verdad de la humanidad". Al año siguiente, análogamente, sugirió el tema de "adhesión a la vida", negando explícitamente que "cristianismo" pudiese ser vivido como algo abstracto e inmutable. No se trataba por tanto de partir de las certezas doctrinales o dogmáticas, sino de las búsquedas y problemas de todas las personas, desde la experiencia compartida de proximidad a la condición humana. Moro siempre se atuvo a este modo profundo de ser cristiano. El suyo era un método, una forma de ser, en lugar de un contenido preciso, pero había construido una tendencia a mediar entre posiciones alejadas y muchas veces antitéticas en nombre de su verdad profunda. Las dos dimensiones, la religiosa y la "laica", nunca iban disociadas, ni se contradecían para Moro, aunque fuesen esencialmente independientes. Muchos otros líderes católicos, incluso con sensibilidad "laica", hubiesen intentado una síntesis entre dimensión religiosa y dimensión política, síntesis que no existió en Moro y no por error o por una conciencia ignorante, sino por la comprensión autónomamente "laica" que tenía de la política. Incluso hoy en día se puede opinar que en esto reside su modernidad.

Un tercer elemento es la pertenencia generacional original, vivido como un lugar de construcción de una identidad común y no de confrontación. Su historia fue como el comienzo de muchos jóvenes en la vida política después de la guerra, pero, también en este caso, con un perfil distintivo. Los historiadores han descrito muy bien a aquella minoría de jóvenes que pronto se decantaron contra la dictadura, comprometiéndose generosamente con riesgo y sacrificio personal en la actividad clandestina; por otra parte conocemos con precisión los acontecimientos de los otros los desengañados del régimen, los que creyeron hasta el límite en los mitos del heroísmo, el sacrificio, el poder o la violencia. En cambio la historia de muchos jóvenes italianos que no pertenecían ni al primer ni al segundo grupo parece algo borrosa. En los últimos meses he trabajado mucho en el archivo personal del Moro en el que existe una correspondencia de los años de guerra compuesta por millares de cartas a jóvenes italianos, miembros de la FUCl, miembros de la Acción católica meridional, militantes, estudiantes de la universidad de Bari, estudiantes que fueron sus alumnos en el liceo. Lo primero que sorprende en este enorme esfuerzo para escribir y mantenerse en contacto es que el fascismo, Mussolini, el régimen no son mencionados ni aparecen en ningún lugar. Incluso aquellos que están a punto de marchar al frente y se declaran dispuestos al sacrificio por sus compañeros y por su patrias, tan sólo piden cercanía humana y oración, en lugar de "camaradería", exigen atención personal y afecto, no hablan de victoria y, en lugar de "odio al enemigo", expresan sus sentimientos de cercanía ante el sufrimiento de todos los 
pueblos e incluso simpatía por todos los jóvenes que luchan como ellos al otro lado de las trincheras, con deseos y esperanza de la paz futura; se dirigen a Aldo pero como modelo de vida intelectual y espiritual, no como a un jefe. Estos jóvenes ni hicieron ni habían de hacer nunca acción clandestina y, sin embargo, reafirman el horizonte lejano de sus ideales para un mundo futuro más justo y más libre que los ideales del fascismo, o como decían para escapar de la censura, "de la masa". Es un poco como si, entre fascismo y antifascismo militante, esta generación estuviese en "otro lugar", transmitiendo un rechazo de las prácticas y de los valores fascistas más que político, de orden moral y existencial, en un cierto sentido aún más profundo. Pero es justamente esta generación, que se siente unida por la experiencia de la guerra y la derrota, que rechaza un programa de reconstrucción deductivo, abstracto y alejado de la realidad concreta del país y que tiene algunas dificultades para aceptar las previsibles divisiones partidistas que llegarán en un futuro, fue la que contribuyó fundamental y concretamente a la Reconstrucción [de posguerra de Italia; n.d.l.t.t.

No es de extrañar que muchos de esos jóvenes, y con ellos Moro, lleguen al compromiso político sólo después de un largo y no siempre fácil itinerario de compromiso civil. Moro lo comenzó de manera explícita no confesional en la experiencia de la Rassegna de Bari, colaborando con un grupo de jóvenes intelectuales independientes de diversos orígenes políticos y culturales. Ya en octubre de 1943 fue el mismo Moro quien habló a los jóvenes desde Radio Bari y les dijo que "demasiadas veces" el fascismo había hablado de ellos, haciéndoles aparecer como "los creyentes de una fe que no compartíais, los partidarios de una causa que no era la vuestra", subrayó el hecho de que en esa hora, "la hora del renacimiento de la Patria", ellos estaban sin embargo "presentes y activos" con su "corazón auténtico en esta primavera dolorosa [...] de recuperación". Les recordó que habían sido "adelantados", puesto que "la época más oscura y triste de nuestra historia nacional», el régimen, se había acabado "especialmente por la reacción" de su "espíritu" que había "juzgado y condenado" a aquél "en libertad". Y me gusta recordar especialmente hoy que, unos pocos meses después, otro joven de estos había llegado a Bari para unirse al ejército italiano, para luchar contra los alemanes y militar en el Partido de Acción, contando más tarde a Giovanni Moro que había conocido a Aldo y había colaborado con la Rassegna: Carlo Azeglio Ciampi.

Finalmente Moro entró en la Democrazia Cristiana (DC), pues consideró que el partido católico era un centro de equilibrio ideal, capaz de poner de acuerdo en sí las variadas verdades parciales de los "otros": un punto de llegada, por lo tanto, que se basaba histórica y laicamente como una necesidad política y no representaba una determinada pertenencia confesional obvia. De hecho, Moro fue 
uno entre pocos de la nueva generación de jóvenes católicos que profundizaron en los contenidos de la tradición popular de Sturzo o De Gasperi, lo mismo que hizo con la liberal de Croce o la socialista de Silone. Se comprende, pues, que en la Constituyente hubiese podido existir una representación pública que pusiese en escena una batalla entre diferentes culturas políticas, unidas sólo por su rechazo del fascismo; y sin embargo, si hoy releemos su actas, la Asamblea aparece como el lugar de construcción de una cultura política verdadera y ampliamente compartida. No es que Moro no fuese consciente de la naturaleza de la convivencia forzada por el acuerdo constitucional, pero él fue también uno de los que señalaron el gran valor compartido de la convivencia:

Si en el acto de construir una casa en la que tenemos que reunirnos todos para vivir juntos - dijo a la asamblea- no encontramos un punto de contacto, un punto de confluencia, se puede decir que hemos fallado en nuestro propósito. Procedentes de diferentes intuiciones políticas y de diferentes orientaciones ideológicas, sin embargo somos miembros de una única comunidad, la comunidad de nuestro Estado y en él estamos unidos sobre la base de una elemental y simple idea de hombre, que hace común y marca nuestro respeto mutuo de unos hacia otros.

Cuarto elemento. Moro era un "político intelectual". Recuerdo que, siendo yo niño, puesto que vivíamos cerca, le veía durante el verano en Terracina, durante horas, en la terracita frente al mar, inmerso en la lectura de montones enormes de periódicos que le llegaban a las rodillas, en un intento -hoy lo comprendo- de captar profundamente no tanto las maniobras partidistas, sino la vida del país, las características de una sociedad que sentía compleja y discordante, pero cuya primacía sobre la política consideraba sin embargo que debía ser reafirmada y defendida. Para él la política era algo positivo de hecho a partir del momento en que más que sobreponerse a la sociedad, era más capaz de comprender, ordenar y guiar sus demandas. En el Consejo nacional de la DC dijo en 1974:

Un partido que quiera guiar [el país], no puede no entender, no puede no seguir, no puede dejar de asumir la responsabilidad de todo lo que está en el origen de su función política: la realidad concreta de los intereses, los valores, los pensamientos, los ideales en los que se mueve el ciudadano como protagonista de la vida política.

No es sorprendente pues que, al leer ahora los escritos de Moro, se vea poco a poco en ellos surgir una conciencia crecientemente lúcida de la distancia que se estaba creando entre política y sociedad, y de los efectos que este hecho habría podido provocar en la vida colectiva y en la solidez del sistema democrático.

Último elemento. Moro fue "político de la palabra". Ciertamente tenía un estilo muy personal y un orden retórico propio, que se ha convertido en algo casi legendario y objeto de un sinfín de bromas mordaces, debido a la confusión o la oscuridad 
deseada. De hecho, al volver a leer hoy sus intervenciones, son absolutamente claras en sus intenciones y coherentes en sus argumentos, aunque nunca agresivos ni demagógicos. Sin embargo Moro fue capaz de hacerse entender perfectamente en las plazas públicas pues tenía su propia forma de pedagogía popular típica de la etapa de la democracia de los partidos y presentaba la política como el lento aproximarse a la comprensión de los hechos y a las posibles opciones.

En pocas palabras, Moro fue uno de los protagonistas de primer orden de la historia de nuestro país y también un lúcido observador y atento como pocos, capaz en la mayor parte de las ocasiones de explicarle el país a sí mismo; Moro fue un producto importante de esta misma historia. Reflexionar sobre él ayuda a comprender no sólo la Italia de ayer, sino la de hoy y sus problemas; hablar de su vida también ayuda a aclarar algo no secundario sobre la soledad que experimentó durante su secuestro, cuando le pareció percibir puertas cerradas por las decisiones esenciales de su vida y por la calidad de la democracia que su trabajo había producido o facilitado.

En conclusión, ¿̇es posible definir la esencia de la contribución de Aldo Moro a la historia de nuestra República? No es fácil, pero me gustaría proponer brevemente algunas sugerencias.

Moro es sin duda uno de los grandes artífices de lo que hoy somos: contribuyó significativamente a dar a este país su constitución, el milagro económico, la sociedad abierta de los movimientos sociales de los años sesenta y setenta. En noviembre de 1945, en la víspera del proceso que lo llevaría como candidato a las elecciones a la Asamblea constituyente, Moro escribió:

Ciertamente hace falta prudencia para evitar una ruina mayor que la ya vivida. Pero hace falta que la prisa ciega e impulsiva de la revolución dé a nuestros espíritus, que quieren ser cautos y honestos al mismo tiempo, un extraordinario deseo de hacer, porque, más allá de las soluciones demagógicas, para ayudar a este pueblo que renace a alcanzar con dignidad y con esfuerzo su lejana meta.

A este compromiso básico con los italianos y con esta inspiración de fondo en su realización Moro siempre permaneció fiel. Es precisamente por esta razón por la que su figura como político nos parece particularmente importante hoy en día.

En una época en la que la política tiende a simplificar, testimonió el valor de una política de la complejidad. En una época en que los fanatismos y los radicalismos religiosos parecen levantar muros infranqueables y en la que las "trincheras históricas" entre creyentes y no creyentes, cuando las creíamos superadas, parece 
que vuelven a asomarse, como creyente involucrado en la política, Moro recordó que los católicos no son portadores en exclusiva de la verdad. En una época de dificultad de la política, explicó como pocos la crisis y el valor de la política por ella misma. En una época de separación entre las instituciones y el mundo de los jóvenes, manifestó una extraordinaria atención hacia los jóvenes y los problemas de su educación como anticipación esencial del futuro, hasta lograr introducir la educación cívica en la escuela italiana. En la era del mundo global, fue un constructor de redes entre los Estados y entre los pueblos, y fue uno de los primeros en hablar de "opinión pública mundial".

Ésta es la persona de Aldo Moro que hemos de redescubrir como riqueza para el presente y para el futuro de nuestro país. 


\section{Promotio lustitiae}

\section{"Estuve en la cárcel y vinisteis a verme..."}

Desde Australia

Julie Edwards

Desde América Latina

Luis Roblero sj

Desde África

Alfonso Ruiz Marrodán sj

Desde Asia Pacífico

Vilaiwan Phokthavi

Eli Rowdy Y Lumbo sj

Desde Canadá y Estados Unidos

George Williams sj

Michael Kennedy sj

Jose Osuna e Isabel Osuna

\section{Desde Europa}

Leo de Weerdt sj

Desde el Sur de Asia

George Fernando sj

Susai Raj sj

Generosidad y eficacia

Roberto Jaramillo sj

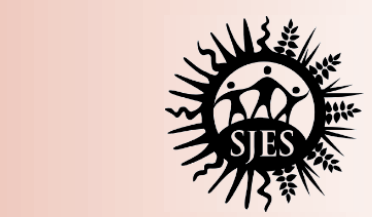

Secretarlado para la Justlcla Soclal

y la Ecología 